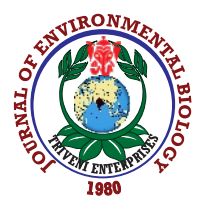

\title{
Induction of genetic variability for quantitative traits in horsegram (Macrotyloma uniflorum) through irradiation mutagenesis
}

\author{
S. Priyanka', R. Sudhagar ${ }^{2 *}$, C. Vanniarajan ${ }^{3}$, K. Ganesamurthy ${ }^{1}$ and J. Souframanien ${ }^{4}$ \\ ${ }^{1}$ Centre for Plant Breeding and Genetics, Tamil Nadu Agricultural University, Coimbatore-641 003, India \\ ${ }^{2}$ Sugarcane Research Station, Melalathur, Tamil Nadu Agricultural University, Vellore-635 806, India \\ ${ }^{3}$ Department of Plant Breeding and Genetics, Agricultural College and Research Institute, Madurai-625 104, India \\ ${ }^{4}$ Nuclear Agriculture and Biotechnology Division, BARC, Mumbai - 400085 , India \\ *Corresponding Author Email : sudhagar.r@tnau.ac.in
}

Aim: The study was conducted to explore the magnitude of variability induced by gamma rays, electron beam and its combinations for quantitative traits in horsegram (Macrotyloma uniflorum (Lam) Verdc.).

Methodology: The horsegram cultivar PAIYUR 2 was irradiated with twelve combinations involving G, EB and G+EB. Desirable mutagenic doses were identified in $\mathrm{M}_{1}$ based on plant injuries and forwarded to M2. Data on 11 yield component traits were recorded on normal looking $\mathrm{M}_{2}$ plants for identification of micro-mutants. Promising mutants were forwarded to $M_{3}$ and the induced variability was ascertained using multivariate statistics.

Results: Significant transgressive variants were observed in $M_{2}$. The G+EB combination induced superior variants for yield. A positive shift in mean for yield and its attributing traits was observed in $\mathrm{M}_{3}$. Most of the polygenic traits were governed by additive gene effects.

Interpretation: The increased mean for most of the polygenic traits in $\mathrm{M}_{3}$ population proved that selection made on early generation was highly effective. The isolated high yielding mutant progenies of selected families will contribute towards yield improvement in horsegram.

Key words: Electron beam, Gamma rays, Horsegram, Induced variability

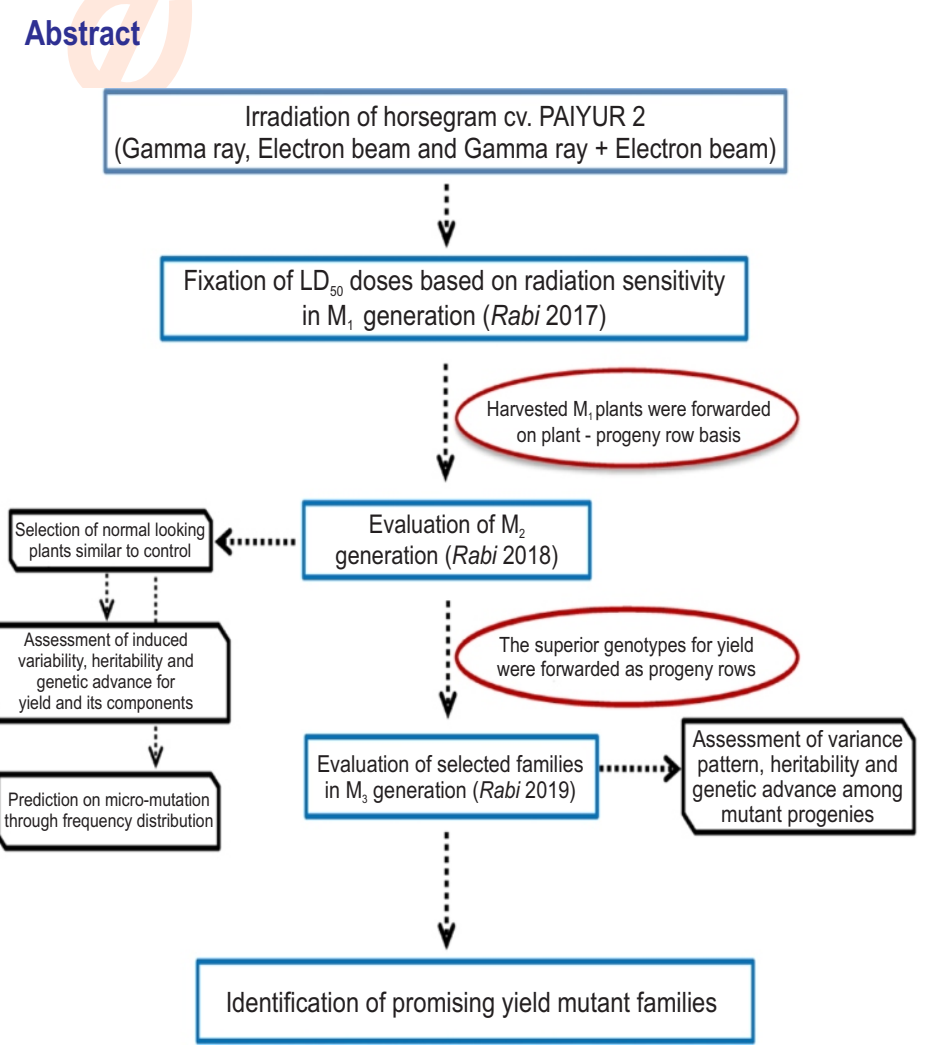

How to cite : Priyanka, S., R. Sudhagar, C. Vanniarajan, K. Ganesamurthy and J. Souframanien: Induction of genetic variability for quantitative traits in horsegram (Macrotyloma uniflorum) through irradiation mutagenesis. J. Environ. Biol., 42, 597-608 (2021). 


\section{Introduction}

Horsegram (Macrotyloma uniflorum (Lam) Verdc.) is an autogamous crop under leguminous family with maturity duration of 120 - 180 days (Morris, 2008). It is well adapted to low rainfall areas with average temperature ranging from $18^{\circ}$ to $27^{\circ} \mathrm{C}$. The seeds are highly nutritious with $16.9-30.4 \%$ protein content (Patel et al., 1995), 51.9 - 60.9\% carbohydrates and $0.58-2.06 \%$ low lipid content (Bravo et al., 1999; Sodani et al., 2004), lysine (Gopalan, 1989), molybdenum (Bravo et al., 1999), phosphorous, iron, and vitamins viz., carotene, vitamin C, riboflavin, niacin and thiamine (Sodani et al., 2004). It is commonly known as poor man's pulse crop because of its drought tolerant nature with enriched health benefits satisfying the nutritional and economic requirement of marginal farmers. This multipurpose legume is primarily cultivated as a food crop in India, Mauritius, Malaysia, Myanmar, Sri Lanka and Nepal, while as fodder crop in Africa and Australia (Asha et al., 2006). In India, horsegram occupies an area of 3.25 lakh ha with a production and productivity of 1.16 lakh tones and $355 \mathrm{~kg} \mathrm{ha}^{-1}$, respectively. Southern India is well thought-out as centre of origin for cultivated species of horsegram (Vavilov, 1951; Zohary, 1970).

The crop is highly photo-sensitive with limited productivity that has led to the replacement of horsegram cultivable areas with other crops. Scientific interventions in horsegram would highly facilitate the crop improvement thereby providing nutritional security in the developing countries. Exploitation of variability for yield, crop duration and ideal stature types would provide an opportunity for evolving superior agronomic types. Chahota et al. (2013) reported the existence of limited variability for desirable traits in Indian germplasm accessions. Moreover, hybridization followed by selection remains futile in horsegram because of small floral buds, extreme flower drop and low percentage of pod set (3-4\%). Adoption of induced mutagenesis would ease crop improvement with shorter time period (Manjaya and Nandanwar, 2007). Horsegram being a diploid crop ( $2 n=20$ and 24$)$, the probability of evolving mutants remains high providing maximum opportunities for selection. Earlier attempts were made on induced mutations in horsegram to explore the effectiveness of different physical (Bolbhat and Dhumal, 2009; Patel et al., 2010) and chemical mutagens (Bolbhat et al., 2012; Kulkarni and Mogle, 2013), but reports on electron beam and its combinations are meagre. Induction of variability through electron beam was found equally effective in relation with gamma rays in legume species (Joshi-Saha et al., 2015; Souframanien et al., 2016). With these views, the experimental study was undertaken to explore the effect of gamma rays $(G)$, electron beam (EB) and combined treatment of gamma rays and electron beam $(G+E B)$ in inducing variability for yield and its related components in horsegram.

\section{Materials and Methods}

A well adopted, horsegram cultivar "PAIYUR 2" released from Tamil Nadu Agricultural University (TNAU), India was utilized for inducing of variability through mutagenesis. Irradiations were carried out at BhabhaAtomic Research Center (BARC), Trombay, Mumbai, India. The mutagen treated seeds viz., $100 \mathrm{~Gy}, 200 \mathrm{~Gy}$, $300 \mathrm{~Gy}$ and $400 \mathrm{~Gy}$ of gamma rays, electron beam and G + EB were sown in a randomized block design with two replications, which constituted $M_{1}$ population. Assessment of plant injuries at $M_{1}$ generation a paved way in determining suitable doses for variability induction.

Each $\mathrm{M}_{1}$ plant from 200 Gy and 300 Gy of gamma rays; $100 \mathrm{~Gy}$ and $200 \mathrm{~Gy}$ of electron beam and $100 \mathrm{~Gy}$ of G + EB was harvested individually and forwarded to $M_{2}$ generation following plant to progeny row method during 2018. Data on 12 biometrical traits viz., days to first flowering, days to maturity, plant height $(\mathrm{cm})$, pod length $(\mathrm{cm})$, number of primary branches per plant, number of pods per cluster, number of clusters per plant, number of pods per plant, number of seeds per pod, hundred seed weight (g), biological yield (g) and single plant yield ( $\mathrm{g}$ ) were recorded for randomly selected 150 normal looking plants similar to control (PAIYUR 2) in each $M_{2}$ population. The selected individual genotypes on seed yield basis were forwarded to $M_{3}$ generation as progeny rows during 2019. Similar biometrical observations were recorded among the progenies of selected mutant families in $\mathrm{M}_{3}$ generation. All the mutant generations were raised at experimental plot of Department of Pulses, TNAU during Rabiseason.

Commercial package of practices was adopted with a spacial pattern of $30 \times 15 \mathrm{~cm}$ in all generations. High order statistics viz., skewness and kurtosis (Snedecor and Cochran, 1967) were performed in $M_{2}$ population for each mutagen to determine the magnitude of induced micro-mutations. The biometrical data of $\mathrm{M}_{2}$ and $\mathrm{M}_{3}$ population were utilized to estimate mean, range, genotypic coefficient of variation (GCV), phenotypic coefficient of variation (PCV) (Burton, 1952), broad sense heritability $\left(H^{2}\right)$ (Lush, 1940), genetic advance as percent of mean (GAM) (Johnson et al., 1955) which provide information on nature and magnitude of variability present in the segregating population and the extent of trait improvement over selection. The estimation of first, second and high order statistics for segregating population are as follows:

First and second order statistics: The variance obtained from the control was taken as error variance $\left(\sigma^{2} e\right)$. The occurrence of variance in mutant population was considered as phenotypic variance $\left(\sigma^{2} p\right)$. The genotypic variance $\left(\sigma^{2} g\right)$ was given by the difference between phenotypic and error variance.

$$
\begin{aligned}
& \text { Genotypic Coefficient of Variation }(G C V)=\sqrt{ }\left(\sigma^{2} g\right) / \text { Mean } \times 100 \\
& \text { Phenotypic Coefficient of Variation }(P C V)=\sqrt{ }\left(\sigma^{2} p\right) / \text { Mean } \times 100 \\
& \text { Heritability }(B . S)\left(H^{2}\right)=\left(\sigma^{2} g / \sigma^{2} p\right) \times 100 \\
& \text { Genetic Advance }(G A)=\left(\sigma^{2} g / \sigma^{2} p\right) \times k \times \sqrt{ }\left(\sigma^{2} p\right)(k=\text { selection } \\
& \text { differential) }
\end{aligned}
$$

High order statistics: The frequency distribution pattern was assessed in $M_{2}$ population by the estimates of skewness $\left(\beta_{1}\right)$ and kurtosis $\left(\beta_{2}\right)$ using SPSS software. 


$$
\begin{gathered}
\text { Skewness }=\frac{\left(n \sum(Y-\mu)^{3}\right.}{(n-1)(n-2) \sigma^{3}} \\
\text { Kurtosis }=\frac{n(n+1) \sum(Y-\mu)^{4}}{(n-1)(n-2)(n-3) \sigma^{4}}-\frac{3(n-1)^{2}}{(n-2)(n-3)}
\end{gathered}
$$

$n$ is the number of observations; $Y$ is the individual observation; $\mu$ is the sample mean and $\sigma$ is the standard deviation.

\section{Results and Discussion}

Improvement of yield and its related components were found promising in many legume species through induced mutagenesis. Datir (2016) reported the effectiveness of conventional mutagens (gamma rays, ethyl methane sulphonate, sodium azide and combinations) in generation of variants for polygenic traits in horsegram. The mutation induction through electron beam has proved to be promising because of its high absorbed dosage rate than gamma rays and other radiations (Zhu et al., 2008). The high dosage rate results in increased double stranded DNA breaks leading to induction of several mutations in a population. Therefore, the present study was undertaken to explore the extent of variability induced by gamma rays, electron beam and its combinations in horsegram.

Statistical analyses on $\mathrm{M}_{2}$ population would be highly beneficial in predicting the induction of micro-mutations (Scossiroli, 1977; Oladosu et al., 2016). Most of the mutant population of $M_{2}$ generation exhibited low average mean compared to control for all quantitative traits, except days to first flowering, days to maturity and plant height (Table 1). The shift in mean towards negative direction resulted due to the deleterious effect of employed mutagens on yield component traits. The prolonged duration in flowering and maturity among mutant population has been reported earlier by Rudraswami et al. (2006) in horsegram and Manjaya and Nandanwar (2007) in soybean.
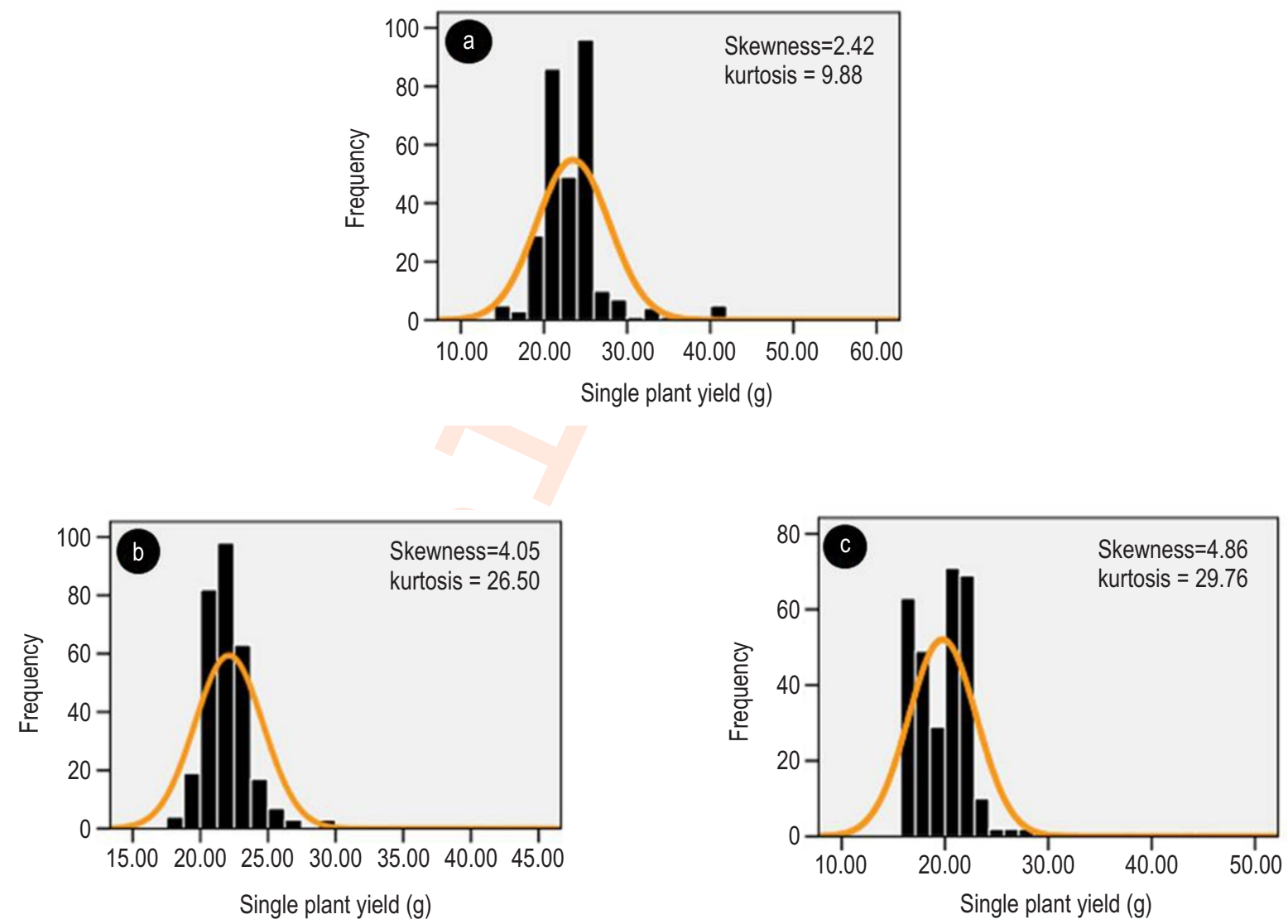

Fig. 1: Frequency distribution pattern of $\mathrm{M}_{2}$ generation for single plant yield in the irradiated population of: (a) gamma rays; (b) electron beam and (c) gamma rays+electron beam. 


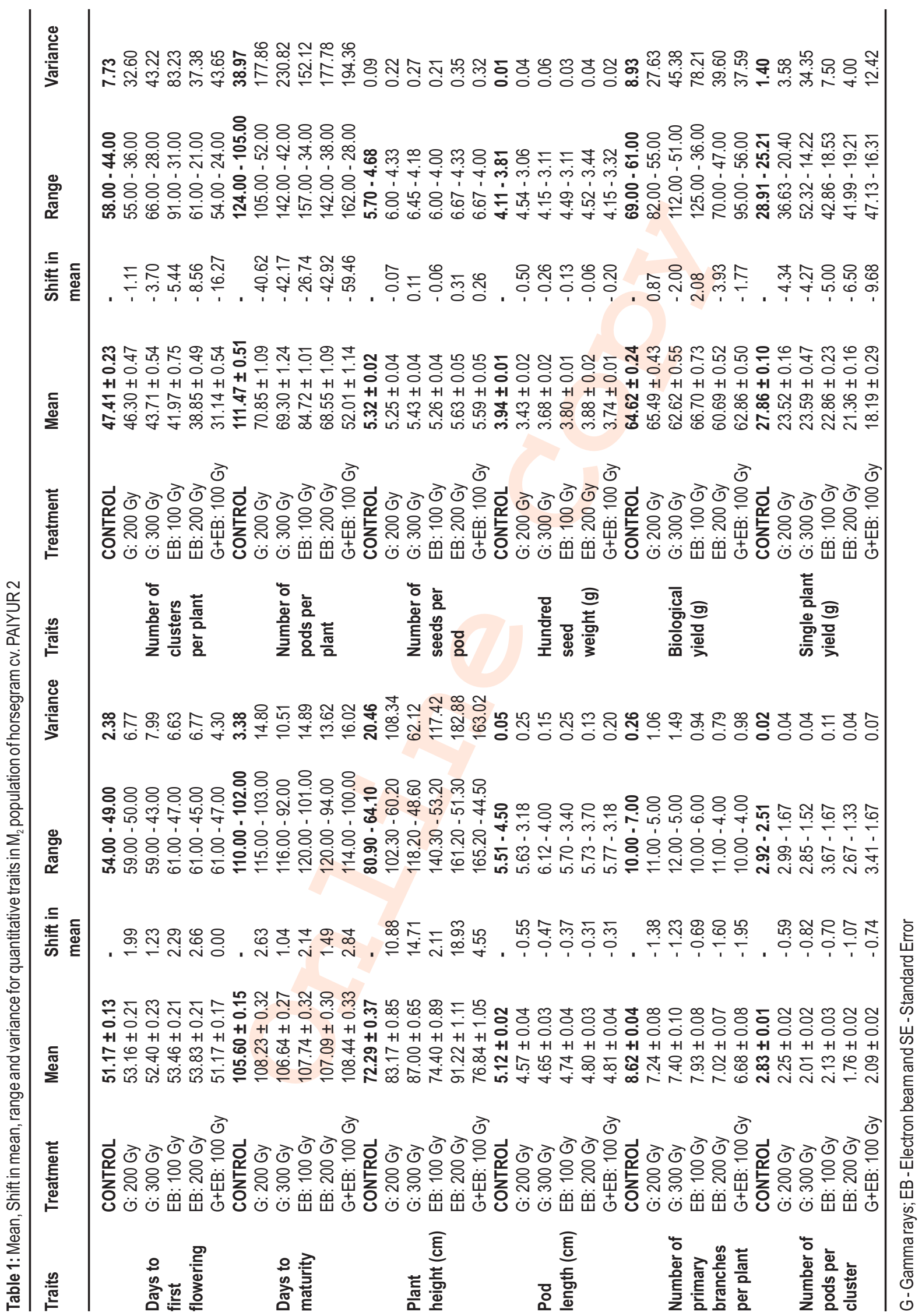


Table 2: Estimates of frequency distribution pattern in $\mathrm{M}_{2}$ population of horsegram cv. PAIYUR 2

\begin{tabular}{|c|c|c|c|c|c|c|c|}
\hline Traits & Treatments & Skewness & Kurtosis & Traits & Mutagen & Skewness & Kurtosis \\
\hline & $G$ & -0.21 & 0.23 & & $G$ & $0.59^{*}$ & -0.48 \\
\hline \multirow[t]{3}{*}{ Days to first flowering } & $\mathrm{EB}$ & $-0.44^{*}$ & 0.41 & Number of clusters & EB & $2.14^{*}$ & $10.40^{*}$ \\
\hline & $G+E B$ & $-0.49^{*}$ & $2.48^{*}$ & per plant & $G+E B$ & $0.61^{*}$ & -0.09 \\
\hline & $G$ & $0.38^{*}$ & 0.32 & & $G$ & $0.58^{*}$ & $1.06^{*}$ \\
\hline \multirow[t]{3}{*}{ Days to maturity } & $\mathrm{EB}$ & $0.89^{*}$ & $2.17^{*}$ & Number of pods & EB & $0.51^{*}$ & $5.19^{*}$ \\
\hline & $G+E B$ & 0.35 & $-1.47^{*}$ & per plant & $G+E B$ & $3.42^{*}$ & $25.10^{*}$ \\
\hline & $\mathrm{G}$ & -0.18 & $0.94^{*}$ & & $G$ & 0.10 & $-0.89^{*}$ \\
\hline \multirow[t]{3}{*}{ Plant height (cm) } & $\mathrm{EB}$ & $1.54^{*}$ & $5.42^{*}$ & Number of seeds & EB & -0.07 & -0.51 \\
\hline & $G+E B$ & $3.71^{*}$ & $20.23^{*}$ & per pod & $G+E B$ & $-0.47^{*}$ & -0.18 \\
\hline & $G$ & 0.02 & 0.14 & & $G$ & $0.48^{*}$ & 0.41 \\
\hline \multirow[t]{3}{*}{ Pod length (cm) } & $\mathrm{EB}$ & $-0.30^{*}$ & 0.39 & Hundred seed & EB & 0.18 & $2.79^{*}$ \\
\hline & $G+E B$ & $-0.72^{*}$ & 0.74 & weight (g) & $G+E B$ & 0.23 & $2.07^{*}$ \\
\hline & $\mathrm{G}$ & $0.51^{*}$ & $1.21^{*}$ & & $\mathrm{G}$ & $2.59^{*}$ & $15.60^{*}$ \\
\hline Number of primary & $\mathrm{EB}$ & 0.17 & 0.26 & Biological yield (g) & $\mathrm{EB}$ & $1.86^{*}$ & $15.73^{*}$ \\
\hline \multirow[t]{4}{*}{ branches per plant } & $G+E B$ & $0.99 *$ & $0.91^{*}$ & & $G+E B$ & $1.97^{*}$ & $5.05^{\star}$ \\
\hline & $G$ & $0.47^{*}$ & $1.36^{*}$ & & $G$ & $2.42^{*}$ & $9.88^{*}$ \\
\hline & $\mathrm{EB}$ & $1.24^{*}$ & $2.39^{*}$ & Single plant yield (g) & EB & $4.05^{\star}$ & $26.50^{*}$ \\
\hline & $G+E B$ & $0.83^{*}$ & $3.86^{*}$ & & $G+E B$ & $4.86^{*}$ & $29.76^{*}$ \\
\hline
\end{tabular}

G - Gamma rays; EB - Electron beam; * Significant at $0.05 \%$

Both positive (G: 300 Gy; EB: 200 Gy and G + EB: 100 Gy) and negative shift (G: $200 \mathrm{~Gy}$ and $\mathrm{EB}: 100 \mathrm{~Gy}$ ) in mean value were noticed for number of seeds per pod among mutagenic treatments of PAIYUR 2. A decline in number of seeds per pod was observed earlier by Bolbhat and Dhumal (2012) in gamma rays and EMS treated population of horsegram. A similar trend was registered for single plant yield in all mutant population of PAIYUR 2 with the highest reduction at G + EB combination ($9.68 \mathrm{~g})$. A decline in yield may be attributed to frequent occurrence of deleterious alleles in a population. However, several superior mutants were identified in all treatments with increased yield range than control. All the mutagenic treatments exhibited wide range of variation as compared to control (Table 1) indicating the occurrence of micro-mutants in a positive and negative direction for the studied traits. High order statistics viz., skewness $\left(\beta_{1}\right)$ and kurtosis $\left(\beta_{2}\right)$ provide a better insight in predicting the magnitude and direction of micro-mutations in a population (Misra et al., 2008; Kar et al., 2019). Most of the mutant population exhibited significant skewness and kurtosis indicating the potentiality of employed mutagens in induction of variants (Table 2).

The positive skewed distribution (G: 2.42, EB: 4.05 and G+EB: 4.86) with leptokurtic curve (G: 9.88, EB: 26.50 and G+EB: 29.76) was registered for single plant yield in all irradiated treatments. It implies the occurrence of micro-mutants towards reduction in trait value with presence of extremities over the control range in a population (Fig. 1). Similarly, a leptokurtic curve with skewed pattern towards right was registered in all treated population for biological yield, number of pods per plant, number of pods per cluster and plant height. A sharp curve signifies the presence of outliers or extreme variants in the population providing scope for concerned trait improvement.
Adoption of intense selection in mutant population will result in genetic gain for these traits (Roy, 2000).

The electron beam irradiated population exhibited nonsignificant skewness and kurtosis for number of primary branches per plant $\left(\beta_{1}: 0.17\right.$ and $\left.\beta_{2}: 0.26\right)$ and number of seeds per pod $\left(\beta_{1}:-\right.$ 0.07 and $\left.\beta_{2}:-0.51\right)$ indicating random occurrence of micromutants at both directions. Balint et al. (1968) reported equal distribution of micro-mutants in either direction for most of the polygenic traits. The induction of micro-mutants with increased trait value was noticed in electron beam $\left(\beta_{1}:-0.44\right)$ and its combination $\left(\beta_{1}:-0.49\right)$ treatment for days to first flowering. $A$ flattened curve than normal (Platykurtic) was exhibited by $G+E B$ $\left(\beta_{2}:-1.47\right)$ mutant population indicating less frequency of superior mutants for maturing duration. The occurrence of variants with increased value for pod length was noticed in electron beam $\left(\beta_{1}:-\right.$ $0.30)$ and its combination with gamma rays $\left(\beta_{1}:-0.72\right)$. From the estimates, it is evident that mutagens were potential in inducing extreme variant types for most of the yield components. The occurrence of transgressive variants was analyzed to determine the scope of isolating mutants with improvement in yield component traits (Misra et al., 2008).

The estimates provide clear picture on the extent of variation induced by the mutagens in comparison with control (Table 3). The genotype of $\mathrm{M}_{2}$ population possessing value higher than the highest trait value of control was considered as positive transgressive variant (PTV) and the trait value lower than the lowest value of control as negative transgressive variant (NTV). The average and maximum transgressive variation were worked out for the PTV's and NTV's to identify the extent of deviations from the control. The negative transgressive variants were 


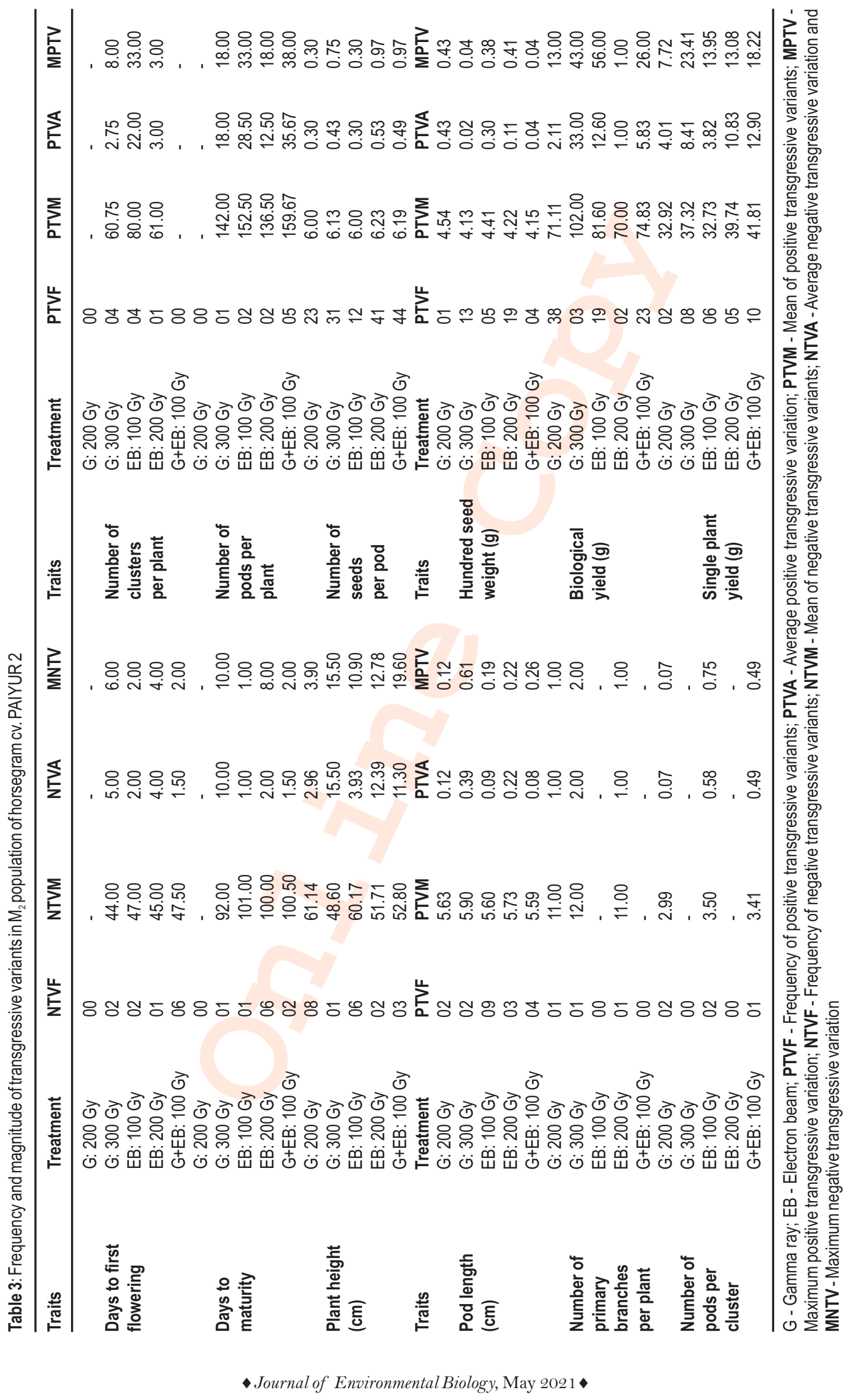


Table 4: Identified desirable doses for the induction of transgressive variants in horsegram cv. PAIYUR 2

\begin{tabular}{ll}
\hline Characters & Mutagenic doses \\
\hline Days to first flowering & G (300 Gy) \\
Days to maturity & EB (200 Gy) \\
Plant height (cm) & G+EB (100 Gy) \\
Pod length (cm) & G (300 Gy) and EB (200 Gy) \\
Number of primary branches & - \\
per plant & \\
Number of pods per cluster & EB (100 Gy) \\
Number of clusters per plant & EB (100 Gy) \\
Number of pods per plant & EB (100 Gy) and G+EB (100 Gy) \\
Number of seeds per pod & EB (200 Gy) and G+EB (100 Gy) \\
Hundred seed weight (g) & EB (100 Gy) \\
Biological yield $(\mathrm{g})$ & EB (100 Gy) \\
Single plant yield (g) & G (300 Gy), EB (200 Gy) and \\
& G+EB (100 Gy)
\end{tabular}

G-Gamma rays; EB -Electron beam

considered for days to first flowering and days to maturity in this study. The effective doses were selected on the basis of high occurrence coupled with high average and maximum variation from control. The identified promising doses for extreme variants serve as a component in planning for improving of polygenic traits in horsegram (Table 4). Among the mutagens, G + EB: 100 Gy followed by G: 300 Gy induced high frequency (10 and 08) of superior types with high average (12.90 and 8.41) and maximum transgressive variation (18.22 and 23.41) for single plant yield. These mutagenic doses can be employed in future mutation breeding programmes to achieve extreme variants with enhanced yield (> $8 \mathrm{~g}$ ) over control. The high frequency (06) of early duration types was noticed in 200 Gy electron beam irradiated population exhibiting variation range of 2 (NTVA) to 8 (MNTV) days over control. A wide variation was noticed among mutagenic treatments for occurrence of transgressive types. Among the mutagens, lower dose of electron beam (100 Gy) were found promising in inducing extreme variants for most of the studied yield component traits.

The estimates of mean \pm standard error, shift in mean, range and variance of $\mathrm{M}_{3}$ population are presented in Table 5. The shift in mean towards positive and negative direction was observed in mutagenic treatments which contributed towards increased variance over control. Among mutagens, combination of $G+E B$ exhibited the highest shift in mean value for single plant yield $(11.57 \mathrm{~g})$, number of clusters per plant (38.33) and number of pods per plant (17.40). The increased plant height $(146.37 \mathrm{~cm})$ coupled with biological yield $(121.26 \mathrm{~g})$ in $300 \mathrm{~Gy}$ of gamma rays irradiated population seems to be useful for evolving mutant lines with superior fodder value. The extreme range than control was noticed for most of the yield component traits in mutant progenies of $\mathrm{M}_{3}$ population. Implementation of selection on mutant progenies would assist in identifying promising lines with improved agronomic value. The mean of single plant yield increased from $M_{2}$ to $M_{3}$ generation with induction of superior mutants in all irradiated treatments. Imposing direct selection on yield basis in $\mathrm{M}_{2}$ generation could be a reason for positive shift in mean value (Khan and Qureshi, 2006). The extreme mutants yielding more than $70 \mathrm{~g}$ (G: $300 \mathrm{~Gy}$, EB: 200 Gy and $\mathrm{G}+\mathrm{EB}: 100 \mathrm{~Gy}$ ) were isolated in $\mathrm{M}_{3}$ generation, which provide scope for yield enhancement in horsegram. $A$ positive shift in mean was observed at all mutagenic treatments of $M_{2}$ and $M_{3}$ generations for plant height. The increase in mean value over control could be attributed to frequent induction of positive mutations for the trait (Khan and Wani, 2006).

The mean of hundred seed weight, number of clusters per plant, number of pods per plant and biological yield had shifted to positive direction in $\mathrm{M}_{3}$ generation. A parallel report of positive shift in mean value for polygenic traits was given by Khan et al. (2004). Contrarily, decreased mean value was registered for number of primary branches per plant in both generations $\left(\mathrm{M}_{2}\right.$ and $\mathrm{M}_{3}$ ) when compared against control. The induction of mutations with detrimental effects could be reason for reduced mean values in treated population (Singh et al., 2000). The mean of days to first flowering and maturity declined in $\mathrm{M}_{3}$ population compared to control with few exceptions. Mutants with reduced duration would escape from yield loss due to terminal drought as horsegram is cultivated with residual moisture after the end of North-East monsoon in Southern India. Similar early maturing genotypes were reported by Nilahayati et al. (2019) in gamma irradiated population of soybean. The shift in mean at both positive and negative directions was noticed in mutant population compared to control for number of seeds per pod. Similar report on quantitative traits was given by Mensah and Obadoni (2007) in groundnut. The extent of variability, heritability at broad sense $\left(\mathrm{H}^{2}\right)$ and genetic advance as percent of mean (GAM) were calculated for $\mathrm{M}_{2}$ (Table 6) and $\mathrm{M}_{3}$ populations (Table 7).

Low to moderate variability existed for most of the yield component traits in $\mathrm{M}_{2}$ generation with few exceptions. The low extent of PCV and GCV was registered for days to first flowering and maturity at both generations. In general, the amount of variability increased in $M_{3}$ generation for most of the yield component traits in comparison with $\mathrm{M}_{2}$ indicating the release of inherent variability. Traits viz., single plant yield, biological yield, number of clusters per plant, number of pods per plant, number of pods per cluster and number of primary branches per plant exhibited high values of PCV and GCV in $\mathrm{M}_{3}$ generation. Increase in variability estimate provides scope for realizing yield improvement through effective selection (Muduli and Misra, 2008). The estimates of heritability and genetic advance are highly useful in predicting the selection response on quantitative traits. In this study, the estimates of $\mathrm{H}^{2}$ and GAM tend to increase in $\mathrm{M}_{3}$ generation for most of the yield component traits with few exceptions. The enhanced heritability in subsequent generation could also be an indicative feature of increased homozygosity of genes for the concerned trait (Wani, 2011). The high $\mathrm{H}^{2}$ coupled with high GAM indicates the governance of additive gene effects 


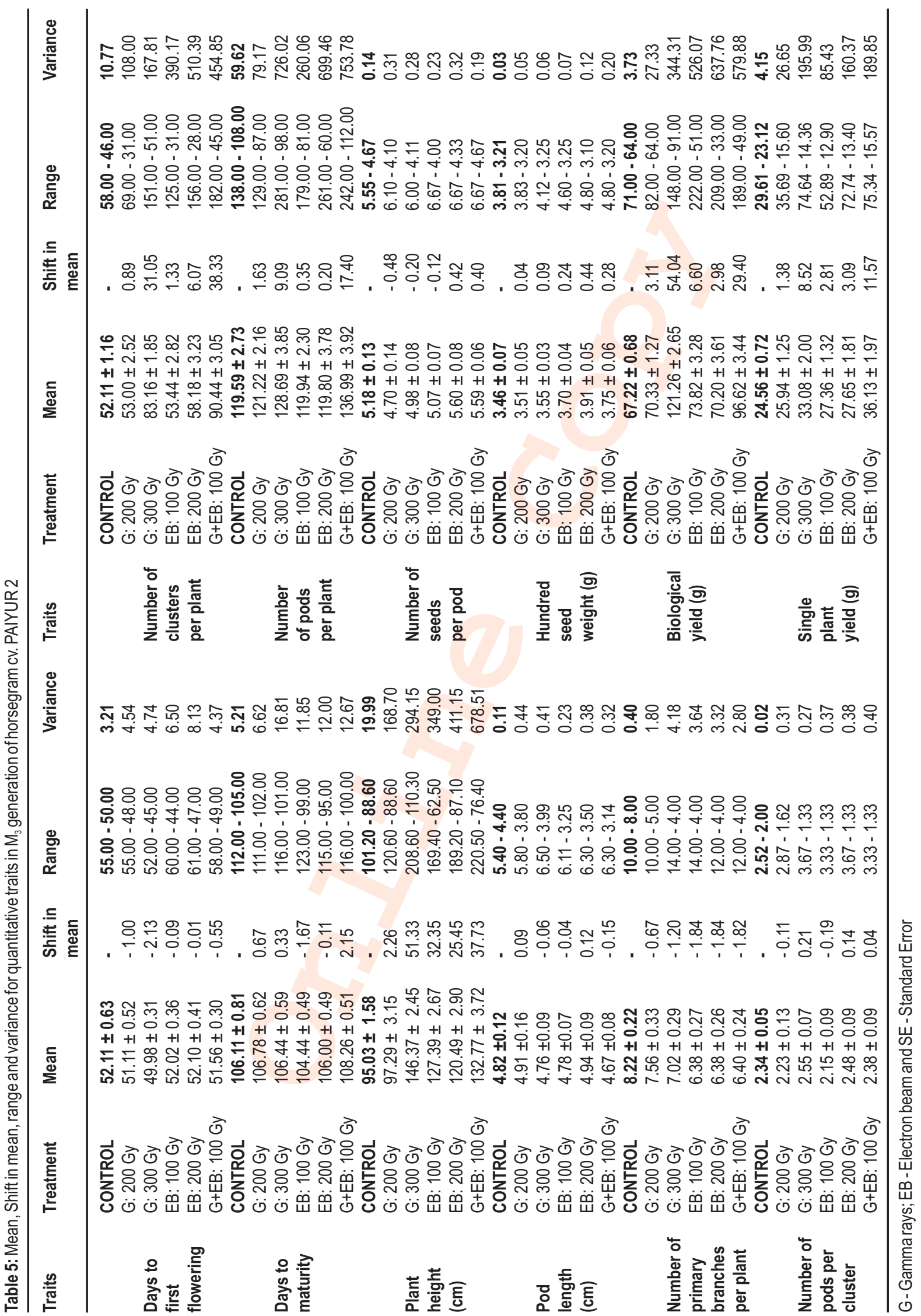




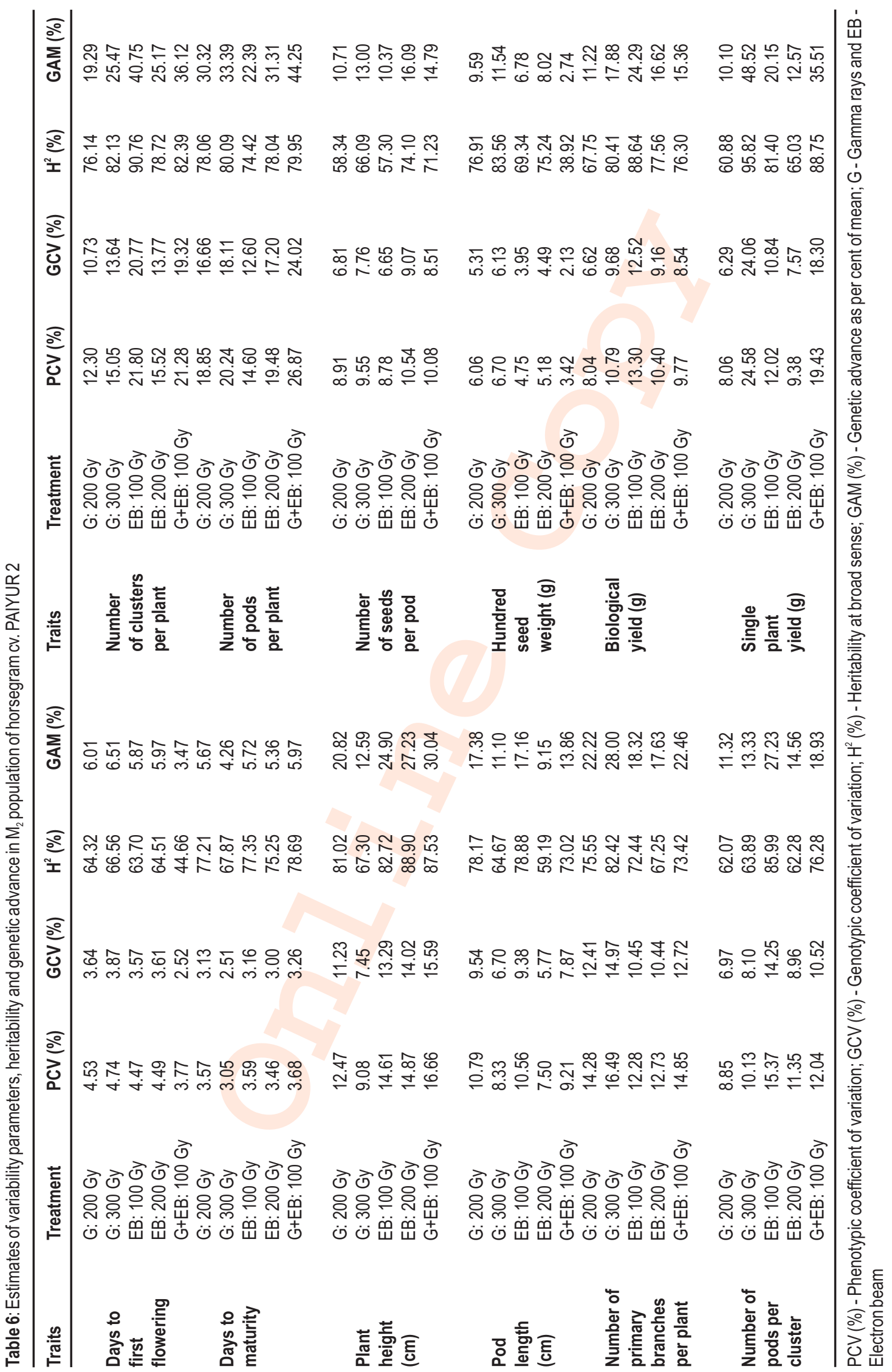




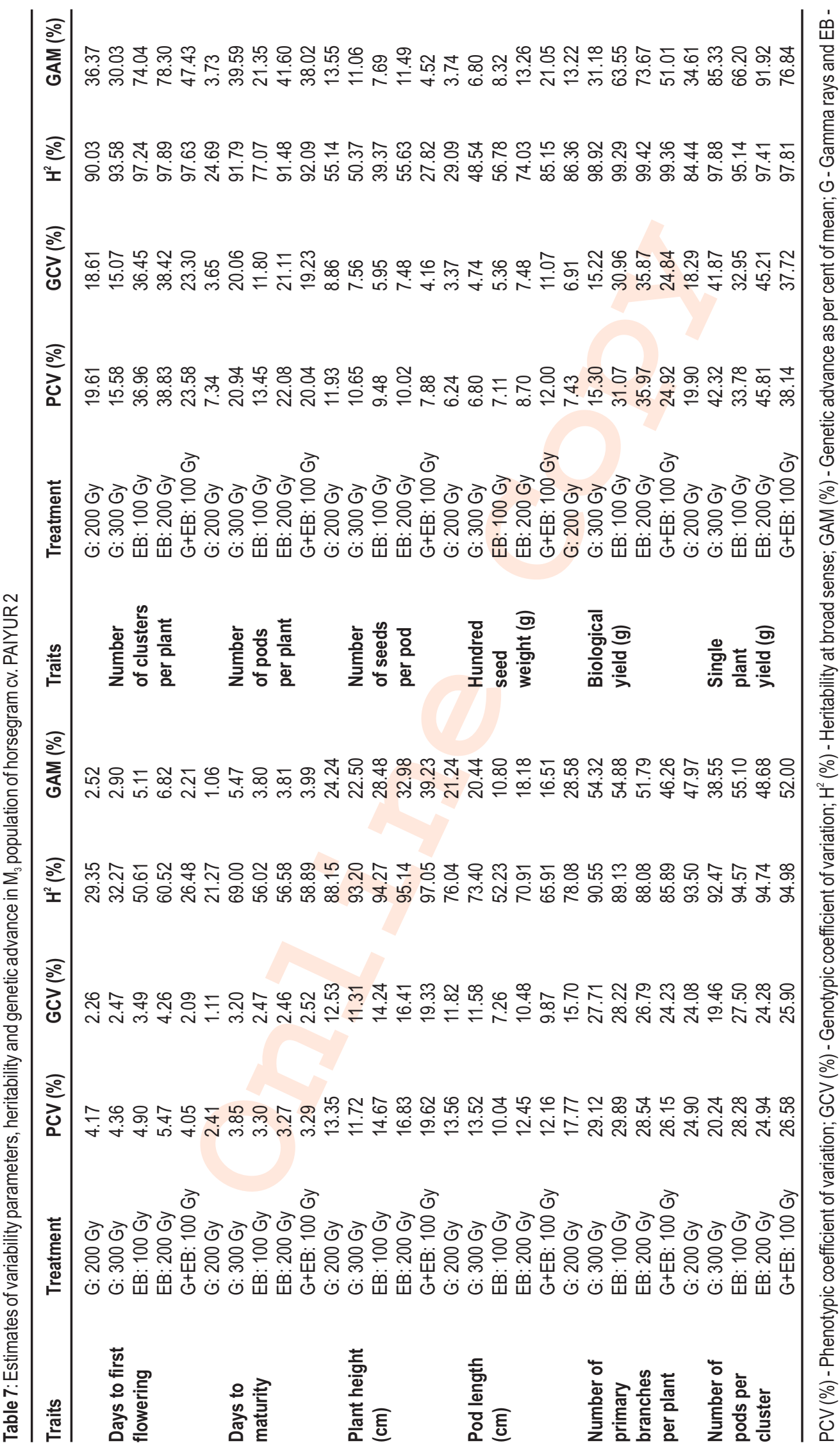


for the studied polygenic traits. Similar findings on quantitative traits were reported earlier by Sheeba et al. (2003) and Mensah et al. (2005). Traits viz., days to first flowering and days to maturity exhibited low to moderate $\mathrm{H}^{2}$ coupled with low GAM at both generations indicating preponderance of non - additive gene action. A significant improvement in mean of yield and its component traits was observed with increased $\mathrm{H}^{2}$ and GAM values. It is evident that selection imposed on $M_{2}$ generation based on single plant yield was highly effective. Similar findings were reported by Solanki and Sharma (2002) in mutant population of lentils. Moreover, variability estimates increased for most of the yield component traits in $\mathrm{M}_{3}$ generation indicating further scope of achieving desirable mutants in advanced generations through selection. In a nutshell, the mutagens used in the study were highly promising for inducing desirable variants in horsegram. The combination of $G+E B$ was found desirable as it exhibited high amount of transgressive variants (PTVF: 10) coupled with improved genetic gain (GAM: $35.51 \%$ ) in $M_{3}$ generation for single plant yield. The stability of isolated high yielding mutant progenies will be test verified in subsequent generation. Thus, the delineated superior mutants offer scope for yield realization in horsegram of Southern India.

\section{Acknowledgments}

We earnestly acknowledge the Board of Research in Nuclear Sciences for providing the financial support and Dr. S. Dutta, Program Officer, Bhabha Atomic Research Centre (BARC), Professor M. Raveendran, Department of Biotechnology, Centre for Plant Molecular Biology and Biotechnology, Tamil Nadu Agricultural University (TNAU) and Professor P. Jeyakumar, Department of Crop physiology, TNAU for their technical assistance towards this experimental study. The authors are highly thankful to Professor P. Jayamani and Head, Department of Pulses, TNAU for her relentless scientific support.

\section{Add-on Information}

Authors' contribution: S. Priyanka: Execution, Data compilation, analysis and manuscript preparation; R. Sudhagar: Conceptualization, methodology, execution, data analysis and supervision; C. Vanniarajan: Data execution, review and editing, fund acquisition; K. Ganesamurthy: Supervision, editing and resources and J. Souframanien: Methodology, review, editing, fund acquisition.

Research content: The research content of manuscript is original and has not been published elsewhere.

\section{Ethical approval: Not applicable}

Conflict of interest: The authors declare that there is no conflict of interest.

Data from other sources: Not applicable
Consent to publish: All authors agree to publish the paper in Journal of Environmental Biology.

\section{References}

Asha, K.I., M. Latha, Z. Abraham, P.K. Jayan, M.C. Nair and S.K. Mishra: Horsegram in India. In: Genetic Resources (Eds.: D. Kumar). Scientific Publisher, Jodhpur, India, p. 11-28 (2006).

Balint, A., D. Dudits and J. Sutka: Study of quantitative characters of pea in a mutant population. Novenytermeles, 17, 187-196 (1968).

Bolbhat, S.N. and K.N. Dhumal: Effect of mutagens on quantitative characters in $\mathrm{M} 2$ and $\mathrm{M} 3$ generation of horsegram (Macrotyloma uniflorum (Lam.) Verdc). Int. J. Sci. Res., 2, 1-7 (2012).

Bolbhat, S.N. and K.N. Dhumal: Induced macromutations in horsegram [Macrotyloma uniflorum (Lam) Verdc]. Legume Res., 32, 278-281 (2009).

Bolbhat, S.N., V.D. Bhoge and K.N. Dhumal: Induced mutations in horsegram [Macrotyloma uniflorum (LAM) VERDC)]: Chlorophyll mutations, mutagenic efficiency and effectiveness. Int. J. Life Sci. Pharma. Res., 2, 159-168 (2012).

Bravo, L., P. Siddhuraju and F. Saura-Calixto: Composition of underexploited Indian pulses. Comparison with common legumes. Food Chem., 64, 185-192 (1999)

Burton, G.W.: Quantitative inheritance in grass. In: Proc. of $6^{\text {th }}$ International Grassland Congress, p. 24-83 (1952).

Chahota, R.K., T.R. Sharma, S.K. Sharma, N. Kumar and J.C. Rana: Horsegram. In: Genetic and Genomic Resources of Grain Legume Improvement, Elsevier Inc. Chapters, pp. 293 (2013).

Datir, S.S.: Genetic improvement in horsegram [Macrotyloma uniflorum (lam) verdc.] (syn. Dolichos biflorus L.) through induced mutations. J. Food Legumes, 29, 174-179 (2016).

Gopalan, C., B.V. Ramashastri and S.C. Balasubramanyan: Nutritive value of Indian foods. National Institute of Nutrition, ICMR, Hyderabad, India (1989).

Johnson, H.W., H.F. Robinson and R.E. Comstock: Estimates of genetic and environment variability in soybean. Agronomy J., 47, 314-318 (1955)

Joshi-Saha, A., K.S. Reddy, V.C. Petwal and J. Dwivedi: Identification of novel mutants through electron beam and gamma irradiation in chickpea (Cicer arietinum L.). J. Food Legumes, 28, 1-6 (2015).

Kar, R.K., T.K. Mishra and B. Pradhan: Studies on frequency distribution, skewness and kurtosis in $\mathrm{F}_{1} \mathrm{M}_{1}$ mutant populations of sesame. Int. J. Curr. Microbiol. App.Sci., 8, 1755-1760 (2019).

Khan, M.R. and A.S. Qureshi: Induced genetic variability in quantitative traits of kabuli chickpea (Cicer arietinum L.). Proc. Pakistan Acad. Sci., 43, 87-94 (2006).

Khan, S., M.R. Wani and K. Parveen: Induced genetic variability for quantitative traits in Vigna radiata (L.) Wilczek. Pakistan J. Bot., 36, 845-850 (2004)

Khan, S. and M.R. Wani: Induced mutations for yield contributing traits in greengram. Int. J. Agri. Bio., 8, 528-530 (2006).

Kulkarni, G.B. and U.P. Mogle: Effects of mutagen on chlorophyll mutation in horsegram [Macrotyloma uniflorum (Lam) Verdcourt]. Biosci. Discov., 4, 214-219 (2013).

Lush, J.L.: Intra-sire correlations and regression of offspring on dams as a method of estimating heritability of characters. Proc. American Soci. Ani. Prod., 33, 293-301(1940).

Manjaya, J.G. and R.S. Nandanwar: Genetic improvement of soybean variety JS 80-21 through induced mutations. Plant Mut. Rep., 1, 36-40 (2007).

Mensah, J.K. and B. Obadoni: Effect of sodium azide on yield parameters of groundnut (Arachis hypogea L.). African J. Biotech., 6, 668-671 (2007). 
Mensah, J.K., P.A. Akomeah and E.O. Ekpekurede: Gamma induced variation of yield parameters in cowpea (Vigna unguiculata (L.) Walp). Global J. Pure. App. Sci., 11, 327-330 (2005).

Misra, R.C., P.K. Sahu, C.R. Jali, H.P. Mishra and L.D. Misra: Studies on skewness, kurtosis and transgressive variation in M2 populations of ricebean (Vigna umbelata) varieties. Legume Res. An. Int. J., 31, 94-99 (2008).

Morris, J.B.: Macrotyloma axillare and M. uniflorum: Descriptor analysis, anthocyanin indexes, and potential uses. Genet. Res. Crop Evol., 55, 5-8 (2008).

Muduli, K.C. and R.C. Misra: Induced polygenic variability in M2 generation and its relationship with production of high yielding mutants in finger millet. Indian J. Genet., 68, 419-425 (2008).

Nilahayati, R., D.S. Hanafiah and F. Harahap: The genotype selection of $\mathrm{M}_{3}$ generation of Kipas Putih soybean with gamma-rays irradiation on agronomic characters, early maturity and high yielding mutants. Bulg. J. Agric. Sci., 25, 97-102 (2019).

Oladosu, Y., M.Y. Rafii, N. Abdullah, G. Hussin, A. Ramli, H.A. Rahim, G. Miah and M. Usman: Principle and application of plant mutagenesis in crop improvement: A review. Biotech. Biotech. Equip., 30, 1-16 (2016).

Patel, D.P., B.S. Dabas, R.S. Sapra and S. Mandal: Evaluation of horsegram [Macrotyloma uniflorum (Lam.) ] germplasm. Nat. Bureau Plant Genet. Res., pp. 37-53 (1995).

Patel, N.B., N.B.S. Tikka and J.B. Patel: Effect of gamma rays on different parameters under laboratory and field conditions in $\mathrm{M} 1$ generation in horsegram. J. Food Legumes, 23, 14-20 (2010).

Roy, D.: Plant Breeding - The analysis and exploitation of variability. Narosa Publishing House, New Delhi, India (2000).

Rudraswami, P., K.P. Vishwanatha and C. Gireesh: Mutation studies in horsegram (Macrotyloma uniflorum (Lam.) Verdc). Proc., LSS2006, BARC, Mumbai, India, pp. 88-89 (2006).
Scossiroli, R.E.: Mutations in characters with continuous variation. In: Manual on Mutation Breeding (Tech. Rep. Serial No. 19). IAEA, Vienna, pp. 118-123(1977).

Sheeba, G., S.M. Ibrahim, P. Yogameenakshi and S. Babu: Effect of mutagens on quantitative traits in M2 generation in sesame (Sesamum indicum L.). Indian J. Genet., 63, 173-174 (2003).

Singh, V.P., M. Singh and J.P. Lal: Gamma rays and EMS induced genetic variability for quantitative traits in urdbean (Vigna mungo (L.) Hepper). Indian J. Genet., 60, 89-96 (2000).

Snedecor, G.W. and W.G. Cochran: Statistical Methods. $6^{\text {th }}$ Edn., Oxford and IBH Publishing Co. Pvt. Ltd., New Delhi, India, p. 593 (1967).

Sodani, S.N., R.V. Paliwal and L.K. Jain: Phenotypic stability for seed yield in rainfed horsegram (Macrotyloma uniflorum (Lam.) Verdc.). In: National Symposium on Arid Legumes for Sustainable Agriculture and Trade, pp. 5-7 (2004).

Solanki, I.S. and B. Sharma: Induced polygenic variability in different groups of mutagenic damage in lentil (Lens culinaris Medik.). Indian J. Genet., 62, 135-139 (2002).

Souframanien, J., K.S. Reddy, V.C. Petwal and J. Dwivedi: Comparative effectiveness and efficiency of electron beam and $60 \mathrm{Co}$ y-rays in induction of mutations in blackgram [Vigna mungo (L.) Hepper]. J. Food Legu., 29, 1-6 (2016).

Vavilov, N.I.: Phyto-geographic basis of plant breeding. Chron. Bota., 13, 13-54 (1951).

Wani, A.A.: Induced polygenic variability for quantitative traits in chickpea var. Pusa-372. Comuni. Sci., 2, 100-106 (2011).

Zhu, H., J.Z. Xu, S.Q. Li, X.Y. Sun, S.D. Yao and S.L. Wang: Effects of high energy pulse-electron beam radiation on biomacromolecules. Sci. China Ser. B: Chem., 51, 86-91 (2008).

Zohary, D.: Centers of diversity and centers of origin. In: Genetic Resources in Plants (Eds.: O.H. Frankel and F. Bennett). Oxford, Blackwell Scientific Publications, pp. 33-42 (1970). 